\title{
Três espécies e duas subespécies novas de Actinote Hübner (Nymphalidae, Heliconiinae, Acraeini) ${ }^{1}$
}

\author{
Márlon Paluch 2, 3; Mirna M. Casagrande ${ }^{2,4} \&$ Olaf H. H. Mielke ${ }^{2,4}$ \\ ${ }^{1}$ Contribuição número 1602 do Departamento de Zoologia, Universidade Federal do Paraná. \\ 2 Laboratório de Estudos de Lepidoptera Neotropical, Departamento de Zoologia, Universidade Federal do Paraná. \\ Caixa Postal 19020, 81531-980 Curitiba, Paraná, Brasil. \\ ${ }^{3}$ Bolsista Doutorado CNPq. E-mail: marlonpaluch@gmail.com \\ ${ }^{4}$ Pesquisador CNPq. E-mail: mibras@ufpr.br; omhesp@ufpr.br
}

\begin{abstract}
Three species and two new subspecies of Actinote Hübner (Nymphalidae, Heliconiinae, Acraeini). Actinote mirnae sp. nov. from Bolivia (Chulumani); Actinote mielkei sp. nov. from Bolivia (Chulumani); Actinote furtadoi sp. nov. from Brazil (Mato Grosso, Diamantino); Actinote morio beckeri ssp. nov. from Brazil (Distrito Federal, Planaltina) and Actinote pellenea giffordi ssp. nov. from Brazil (Distrito Federal, Planaltina) are discribed and illustrated.
\end{abstract}

KEY WORDS. Biodiversity; Neotropical; new species; taxonomy.

RESUMO. Actinote mirnae sp. nov. da Bolívia (Chulumani); Actinote mielkei sp. nov. da Bolívia (Chulumani); Actinote furtadoi sp. nov. do Brasil (Mato Grosso, Diamantino); Actinote morio beckeri ssp. nov. do Brasil (Distrito Federal, Planaltina) e Actinote pellenea giffordi ssp. nov. do Brasil (Distrito Federal, Planaltina) são descritas e ilustradas. PALAVRAS-CHAVE. Biodiversidade; Neotropical; espécies novas; taxonomia.

Actinote Hübner, [1819] inclui espécies impalatáveis, característica assegurada por proteção química devido à toxidade resultante de alcalóides pirrolizidínicos e forte cianogênese detectada em todos os estados; sendo os adultos envolvidos em anéis miméticos müllerianos com baixa variação interespecífica. Estes são motivos pelos quais muitas espécies ainda estão sendo descritas (Brown \& Benson 1974, Brown \& Francini 1990, Penz \& Francini 1996, Francini et al. 2004). D'Almeida (1958) sugeriu que em muitos casos a correta identificação de algumas fêmeas só seria possível a partir de adultos obtidos de uma única postura.

PIERRE (1985a, b, c, 1986, 1987), em seus trabalhos de morfologia comparada de garras tarsais, genitálias masculina e feminina, tampão genital, e análise cladística, considerou o grupo como subfamília Acraeinae; estabelecendo um único gênero, Acraea Fabricius, 1807. Em sua proposta cladística Acraea está dividido em dois subgêneros; Acraea (Acraea) englobando o gênero Bematistes Hemming, 1935 (= Planema Doubleday, 1848), com representantes apenas na região Etiópica, e Acraea (Actinote) incluindo todas as espécies neotropicais e vários grupos de espécies africanas, ou seja, o subgênero Actinote passou a ter representantes nas Américas e no Velho Mundo. Para o autor o gênero Pardopsis Trimen, 1887, monotípico, pode ser incluído como uma tribo dos Argynninae, grupo irmão de Acraeinae.

PierRe (1987), não menciona caracteres das espécies de
Abananote Potts, 1943 e Altinote Potts, 1943 e a possibilidade desses formarem juntamente com Actinote Hübner, [1819] três grupos distintos dentro de Acraea (Actinote), caso seja comprovada a monofilia dessas linhagens (LAmAs 1996).

LAMAS (1995) publicou uma série de comentários taxonômicos e nomenclaturais sobre os ninfalídeos neotropicais, considerando Acraeini como tribo de Heliconiinae com os gêneros Abananote Potts, 1943; Altinote Potts, 1943 e Actinote Hübner, [1819].

Penz \& Djunijanti (2003) realizaram uma análise filogenética para estabelecer as relações entre os gêneros de Heliconiinae, baseado em caracteres morfológicos de adultos e quando possível de imaturos, larva madura e pupa (Penz 1999). O resultado foi representado por quatro tribos: Argynnini, tribo apical com 19 gêneros; Vagrantini com 10 gêneros; Heliconiini com 11 gêneros e Acraeini, tribo basal com os gêneros Acraea, Actinote e Pardopsis, considerando dois gêneros para região Etiópica e um para Neotropical. Nessa análise, não foi utilizada nenhuma espécie de Altinote ou Abananote. Actinote melanisans Oberthür, 1917 e Actinote pellenea pellenea Hübner, [1821], espécies do sul e sudeste do Brasil, representaram o grupo neotropical. Da mesma forma, o gênero Acraea foi analisado com apenas três táxons terminais. Contudo, os autores corroboram a monofilia dos gêneros Acraea e Actinote, embasada em caracteres do tarso, prétarso e genitália masculina.

Revista Brasileira de Zoologia 23 (3): 764-778, setembro, 2006 
Mais recentemente, LAMAs (2004) considera os Acraeini como tribo de Heliconiinae e assim constituídos: Abananote com cinco espécies e nove subespécies; Altinote com quinze espécies e cinquenta e sete subespécies e Actinote vinte e seis espécies e trinta e seis subespécies descritas. Porém, outras duas espécies foram recém descritas, Actinote eberti Francini, Freitas \& Penz, 2004 e Actinote pratensis Francini, Freitas \& Penz, 2004 (FrancinI et al. 2004).

Além dos estudos sistemáticos citados anteriormente para os Acraeini neotropicais, todas as contribuições, excetuando Pierre (1987) e Penz \& D Dunijanti (2003), envolvem ecologia, história natural e taxonomia (D'Almeida 1922, 1925, 1931, 1934, 1935a,b, 1943, 1951, 1958, Brown \& Francini 1990, Brown 1992, Penz \& Francini 1996, Paluch et al. 1999, 2001, 2003, 2005, Francini et al. 2004, 2005), todos trabalhos significativos que podem direcionar um futuro estudo cladístico, focando as relações das espécies neotropicais com os grupos estabelecidos por PIERRe (1987), com intuito de testar a viabilidade da divisão do gênero Acraea em unidades monofiléticas menores.

\section{MATERIAL E MÉTODOS}

Os acrônimos a seguir listados indicam as coleções onde estão depositados os exemplares examinados, como mencionados no final da descrição de cada espécie: (DZUP) Departamento de Zoologia, Setor de Ciências Biológicas, Universidade Federal do Paraná, Curitiba, Paraná, Brasil e (MHNL) Museo de Historia Natural, Lima, Peru.

Para medidas das asas se utilizou os seguintes critérios: asa anterior - comprimento da margem costal (base da asa até o ápice de $\mathrm{R}_{3}$ ), margem externa $\left(\mathrm{R}_{4}\right.$ até $2 \mathrm{~A}$ ) e largura da asa (ápice de $\mathrm{R}_{2}$ até ápice de $2 \mathrm{~A}$ ). Asa posterior - comprimento da margem costal (base até ápice de $\left.\mathrm{Sc}+\mathrm{R}_{1}\right)$, margem externa $\left(\mathrm{Sc}+\mathrm{R}_{1}\right.$ até o ângulo anal em $2 \mathrm{~A}$ ) e maior comprimento da asa (base até o ápice de $\mathrm{M}_{2}$ ).

\section{RESULTADOS}

A seguir é apresentada a nomenclatura utilizada nas diagnoses e descrições das faixas, manchas e ornamentações das asas anteriores e posteriores para ambos os sexos, utilizadas nas diagnoses e descrições, seguindo alguns termos de NıjHout (1991) e adequações de outros utilizados por Penz \& Francini (1996).

\section{Asa anterior}

Coloração (Fig. 1).

Dorsalmente ocorrem seis manchas claras na área subapical. Duas menores, entre a bifurcação de $\mathrm{R}_{2}$ (a menor das seis) e entre $R_{1}-R_{2}$, as quatro maiores são semelhantes no tamanho e na forma retangular, estão limitadas ao espaço entre $R_{5}$. $\mathrm{CuA}_{1}$, este conjunto forma a faixa subapical.

Entre a célula discal e a faixa subapical pode ocorrer em algumas espécies a faixa pós-discal; assim como a subapical é formada por um conjunto de manchas, que estão intercaladas entre as veias $\mathrm{R}_{1}-\mathrm{CuA}_{1}$, com a metade da largura da faixa subapical.
Entre a margem costal e Sc, uma faixa clara marcada como uma linha fina de comprimento variável, corresponde a faixa costal; entre a Sc e R outra faixa similar até a região mediana da célula, forma a faixa subcostal.

$\mathrm{Na}$ célula discal, a faixa intradiscal é dividida em duas porções, uma entre a área basal e a mediana, com a forma de um bastão, com a parte mais estreita voltada para a base, a faixa intradiscal basal. A outra próxima às discocelulares, geralmente quadrangular, variável, forma a faixa intradiscal distal, estas faixas foram designadas como "listra $n^{\circ} 1$ " e "mancha ${ }^{\circ} 2$ " respectivamente por (Penz \& FRANCINI 1996).

Entre a $\mathrm{CuA}_{1}-\mathrm{CuA}_{2}$ mancha clara, em forma de triângulo isósceles, com uma das pontas na bifurcação da $\mathrm{CuA}_{2}$ de tamanho maior que da faixa intradiscal distal, forma a mancha subdiscal.

Entre $\mathrm{CuA}_{2}-2 \mathrm{~A}$, região clara que ocupa $2 / 3$ da área desde a base em direção à margem externa constitui a faixa subdiscal, que pode apresentar um ponto escuro com a mesma coloração do fundo da asa na porção mediana próxima ao cúbito anterior $(\mathrm{CuA})$, o ponto subdiscal.

Abaixo da faixa subdiscal e geralmente com o mesmo comprimento, entre $2 \mathrm{~A}$ e a margem interna, está a faixa marginal interna, que em algumas espécies pode ocupar toda área da membrana alar.

Alguns indivíduos podem apresentar duas pequenas manchas claras próximas à margem externa entre $\mathrm{CuA}_{1}-\mathrm{CuA}_{2}-$ $2 \mathrm{~A}$ nominadas de mancha marginal $\mathrm{n}^{\circ} 1$ e 2 respectivamente, sendo a segunda a maior delas.

Todas as veias são cobertas por escamas, faixas venais (Nijhout 1991), geralmente em tons de castanho escuro, coloração de fundo da asa.

A coloração clara das faixas e manchas varia entre o amarelo e o vermelho alaranjado interespecificamente.

O mesmo padrão dorsal de coloração da asa anterior pode ser observado ventralmente, porém com escamas em tons mais claros, contudo as faixas venais e intervenais presentes entre as veias $\mathrm{R}_{2}-\mathrm{R}_{3}-\mathrm{R}_{4}-\mathrm{R}_{5}-\mathrm{M}_{1}-\mathrm{M}_{2}-\mathrm{M}_{3}-\mathrm{CuA}_{1}-\mathrm{CuA}_{2}-2 \mathrm{~A}$ são escuras e intercaladas em fundo claro, devido aos prolongamentos das manchas da faixa subapical e das manchas marginais.

Áreas ocupadas pelas faixas intradiscais, mancha e faixa subdiscais podem apresentar menos escamas, inseridas espaçadamente, conferindo aspecto semitransparente; essas faixas e manchas são classificadas como vestigiais nas descrições das espécies.

De modo geral as fêmeas são similares com coloração pouco mais clara.

\section{Ornamentação com cerdas (Figs 2, 3 e 5)}

JoRDAN (1913) formou dois grupos de espécies dentro dos representantes de Actinote; grupo mamita, composto por três táxons, A. mamita mamita (Burmeister, 1861), A. mamita mitama (Schaus, 1902) e A. canutia (Hopffer, 1874), onde a membrana alar entre o terço apical das veias da margem externa (ambas as asas), é recoberta apenas por escamas afiladas e cerdas finas 


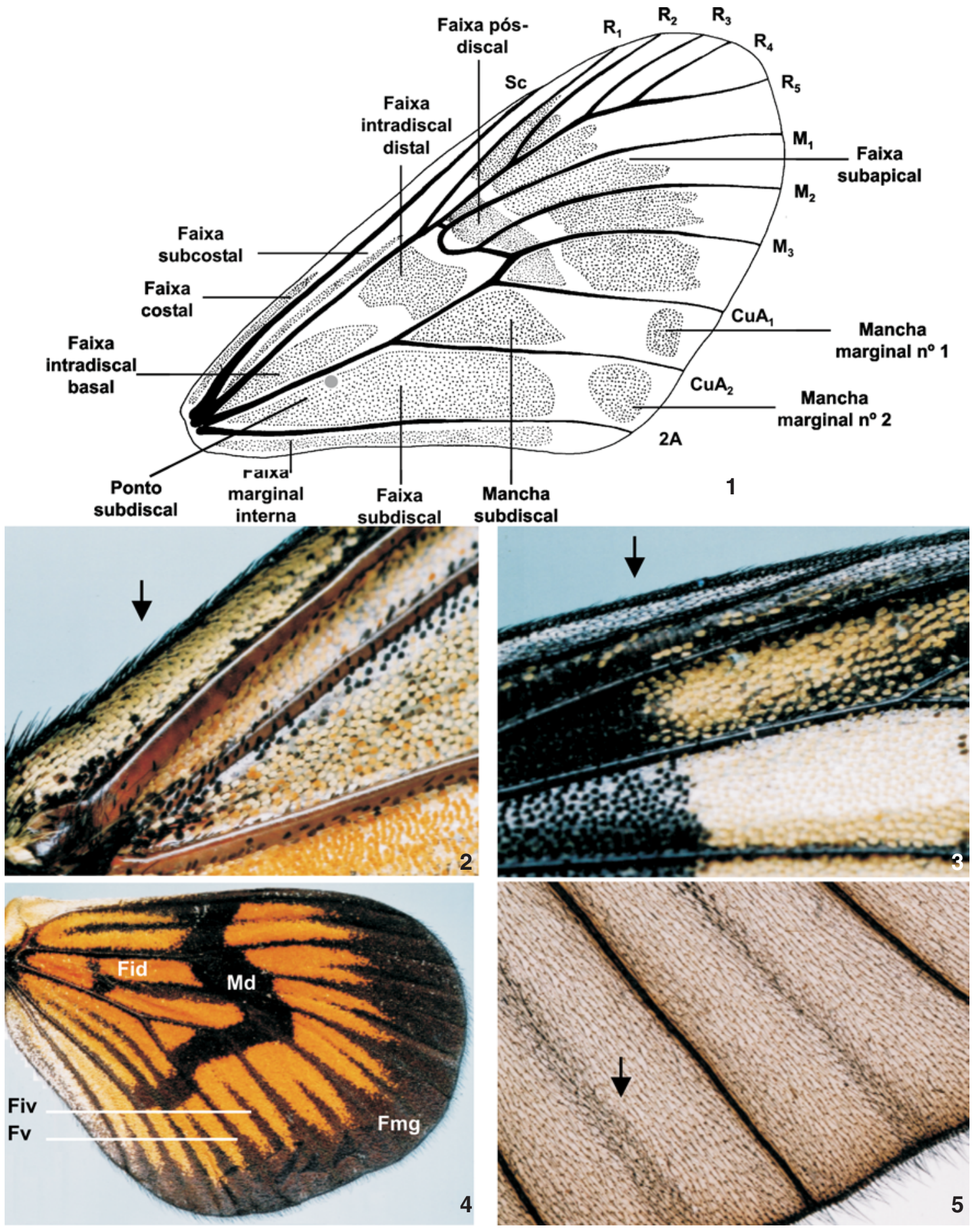

Figuras 1-5. (1) Actinote, asa anterior, vista dorsal, padrão geral da distribuição de faixas e manchas; (2) Actinote melanisans, asa anterior, vista ventral, área costal basal com escamas (ver seta); (3) Actinote melanisans, asa anterior - vista ventral, área costal apical cerdosa (ver seta); (4) Actinote surima surima, asa posterior, vista dorsal, (Md) mancha discal, (Fmg) faixa marginal, (Fid) faixa intradiscal, (Fv) faixa venal, (Fiv) faixa intervenal; (5) Actinote mamita mitama, asa posterior, vista dorsal; faixa marginal cerdosa, faixas intervenais com escamas afiladas (ver seta).

Revista Brasileira de Zoologia 23 (3): 764-778, setembro, 2006 
(Fig. 5); e o grupo thalia, composto pelas demais espécies do gênero, onde a mesma área é recoberta apenas por escamas.

O grupo thalia apresenta uma franja de cerdas simples e bífidas na mesma quantidade (em ambos os sexos); já no grupo mamita ocorrem apenas cerdas simples. Essa franja é formada por 4-6 linhas de cerdas intercaladas na superfície dorsal e ventral da margem costal, ápice, margem externa até 2A, desaparecendo no início da margem interna (PIERRE 1987). Ventralmente $\mathrm{R}_{\mathrm{s}^{\prime}} \mathrm{M}$ e CuA apresentam cerdas esparsas até a margem externa; célula discal fechada por veias tubulares (ЕHRLICH 1958, ACKERY 1984). Membrana alar entre a margem costal e a veia subcostal não é inteiramente revestida por escamas, apenas os 2/3 da porção basal; esse caráter descrito por ELtringHAM \& JORDAN (1913) pode estar presente também na face dorsal de algumas espécies (Figs 2 e 3). Cerdas também estão presentes na membrana alar entre $\mathrm{Sc}-\mathrm{R}_{1}$ próximo à margem costal onde a franja alar é bem visível (Fig. 3).

\section{Asa posterior}

Coloração (Figs 4-5)

Dorsalmente o padrão de faixas e manchas é o mesmo para ambos os sexos, a fêmea é pouco mais clara, mas apresenta praticamente igual quantidade de escamas.

Presença de faixas intervenais, venais (aspecto raiado da asa) e faixa marginal (NijHout 1991).

Faixa marginal pode ser formada apenas por escamas; ou por cerdas nas espécies do grupo mamita (Fig. 5); em ambos os casos, ela é castanho escuro e ocupa desde o ápice da asa até pouco além de $3 \mathrm{~A}$ no ângulo anal, onde se torna afilada; esta faixa geralmente é tão ou mais larga que o tórax. Em algumas espécies apresenta dimorfismo sexual, sendo mais larga na fêmea. Prolonga-se em direção à base da asa formando as faixas intervenais como linha fina e única, com exceção entre $\mathrm{CuA}_{2}-$ $2 \mathrm{~A}$ onde ocorrem duas faixas intercaladas com a dobra venal e pela $1 \mathrm{~A}$; as faixas intervenais são mais largas na base e formadas por escamas arredondadas; porém podem ser afiladas como cerdas no grupo mamita (Fig. 5).

Coloração escura aparece recobrindo todas as veias da asa formando as faixas venais, mais largas na base e próximas a faixa marginal.

$\mathrm{Na}$ célula discal, a faixa intradiscal apresenta-se em forma de bastão. A mancha discal que ocorre sobre ou após as discocelulares (NijHout 1991) é semelhante ao sinal matemático ">" ou a uma "virgula", podendo estar bem marcada em algumas espécies como em A. surima surima (Schaus, 1902) (Fig. 4), ou finamente pontuada após a célula discal como em $A$. alalia (C. Felder \& R. Felder, 1860). Pode ainda ser inconspícua, levemente marcada por uma acentuação na coloração de fundo, em uma ou ambas às faces, com variação intraespecífica.

Entre $2 \mathrm{~A}$ e $3 \mathrm{~A}$ e a margem interna, geralmente com escamas mais claras que o restante da asa.

O mesmo padrão dorsal de coloração das asas posteriores pode ser observado ventralmente em tons mais claros, com algumas exceções. Quando a faixa marginal está ausente em ambas as faces das asas, como em Actinote surima perisa Jordan, 1913 e Actinote lapitha calderoni Schaus, 1920 (sem dimorfismo sexual) as faixas venais e intervenais se prolongam até a margem da asa.

\section{Ornamentação com cerdas}

$\mathrm{Na}$ face dorsal, a membrana alar é inteiramente recoberta por escamas. Cerdas longas e delgadas apenas sobre a membrana da metade proximal da célula discal e no terço proximal entre $2 \mathrm{~A}$ e a célula.

Presença de franja de cerdas simples e bífidas (minoria) em ambos os sexos, que acompanham a margem externa desde $\mathrm{Sc}+\mathrm{R}_{1}$ até o ângulo anal.

$\mathrm{Na}$ face ventral, as veias possuem cerdas castanho-enegrecidas, rígidas e conspícuas distribuídas alternadamente, mais evidentes que na asa anterior. Segundo PIERre (1987), a presença de uma franja de cerdas na margem da asa, assim como, cerdas sobre as veias dos Acraeinae em geral, não é comum entre os Papilionoidea, porém também são encontradas nos Heliconiinae, Argyninae, e Pardopsis.

Entre $\mathrm{CuA}_{2}-2 \mathrm{~A}$, a veia $1 \mathrm{~A}$ é vestigial, delimitando o início da margem interna (PIERRE 1987). Várias cerdas estão inseridas sobre $1 \mathrm{~A}$ e diretamente na membrana, formando uma fileira de cerdas alternadas até a base da CuA, ladeada por duas faixas intervenais.

A célula discal é fechada por veias tubulares (ЕHrLIcH 1958), e pode ou não apresentar uma fileira de cerdas rígidas alternadas dentro da célula na porção central, entre a base da célula e a região mediana da veia dcm, são as cerdas intradiscais (Eltringham \& Jordan 1913, PotTs 1943), este caráter quando presente ocorre em ambos os sexos.

\section{Actinote mirnae Paluch \& Mielke, sp. nov. Figs 6-7, 14-21}

Actinote sp. n. Lamas, 2004. Heliconiinae, p.264, sp. nov., Peru. In: G. Lamas (Ed.). Checklist: Part 4A, Hesperioidea - Papilionoidea, In: J.B. Heppner (Ed.). Atlas Neotrop. Lep. 5A.

Diagnose. Asa anterior com fundo castanho e poucas escamas em ambas as faces; faixas subapical estreita, intradiscal basal-distal, subdiscal e a mancha subdiscal, alaranjadas de aspecto translúcido. Asa posterior com faixas marginal estreita, venais inconspícuas, intervenais largas e longas, intradiscal bem marcada; cerdas intradiscais presentes.

Descrição. Macho (Fig. 6), asa anterior $(\mathrm{n}=3)$ : comprimento da margem costal - 32 a 32,5 mm; margem externa - 18,5 a 19 $\mathrm{mm}$; largura da asa $-17,5$ a $18 \mathrm{~mm}$. Asa posterior $(\mathrm{n}=3)$ : comprimento da margem costal - 21,5 a 22,5 mm; margem externa 15,5 a $17 \mathrm{~mm}$; maior comprimento da asa $-22,5$ a 23,5 mm.

Face dorsal da asa anterior: fundo castanho com poucas escamas; faixas subapical, intradiscal basal-distal, subdiscal e a mancha subdiscal, alaranjado claro de aspecto translúcido. Faixa costal com comprimento igual à largura da cabeça, subcostal apresenta o mesmo comprimento da faixa intradiscal basal,

Revista Brasileira de Zoologia 23 (3): 764-778, setembro, 2006 

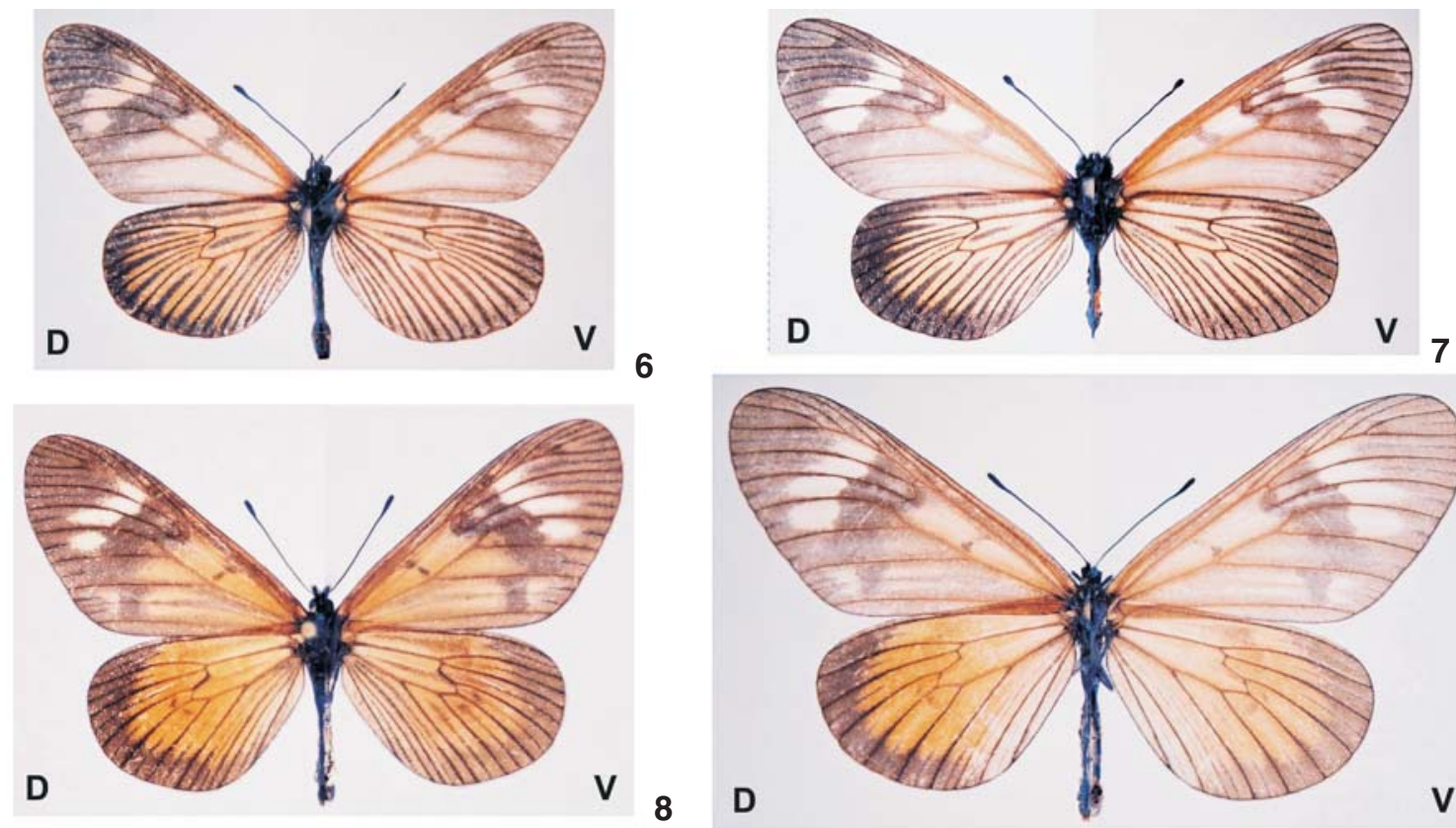

6
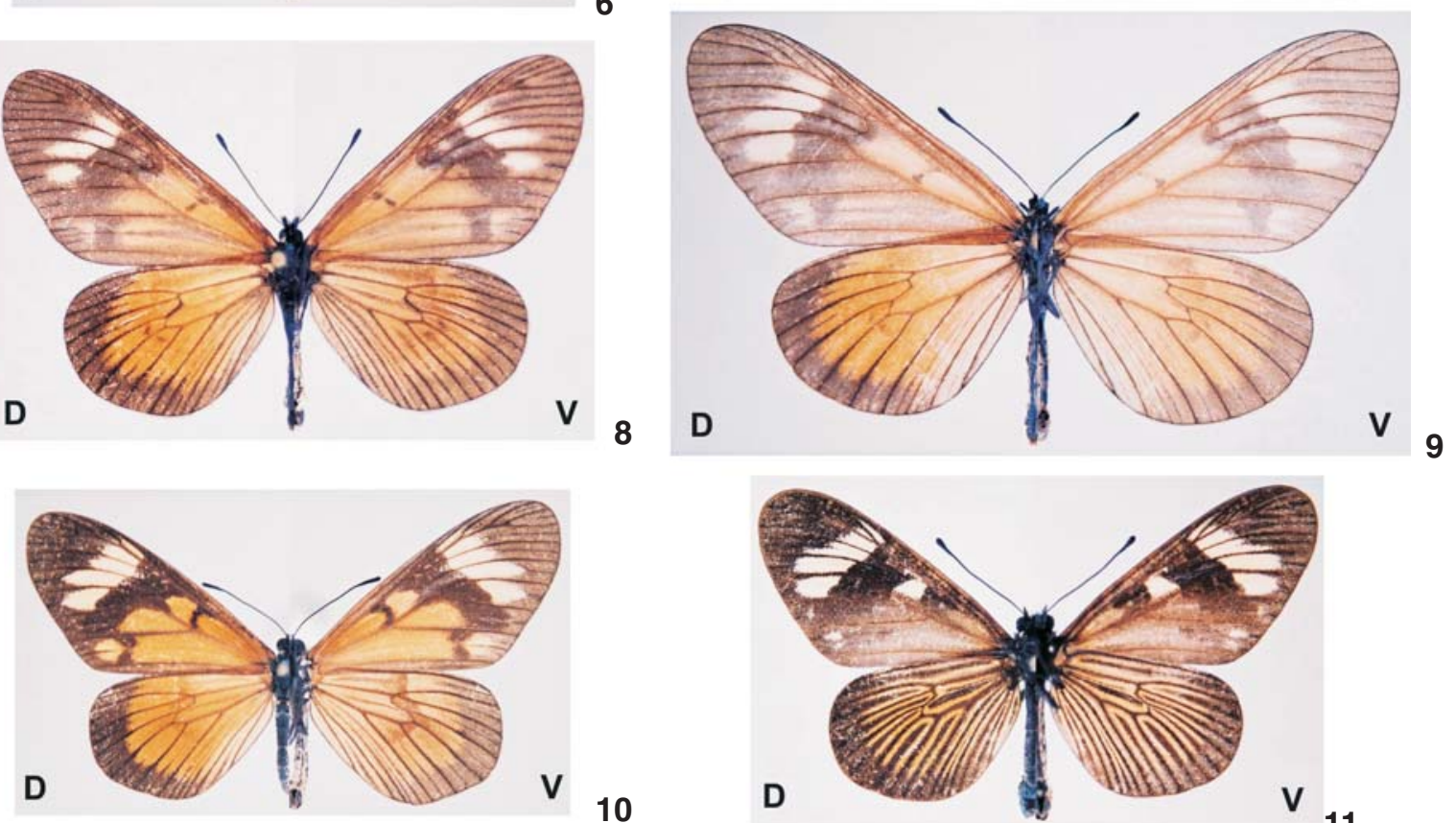

10
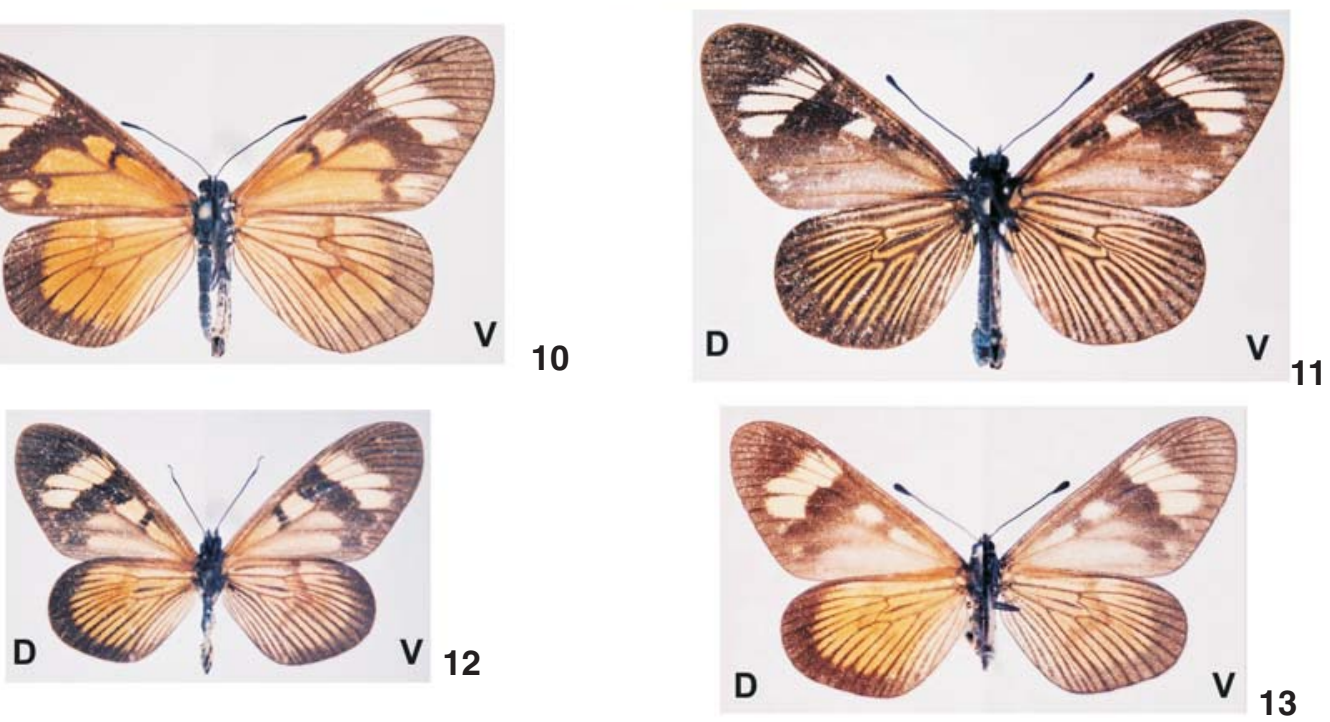

Figuras 6-13. (6-7) Actinote mirnae sp. nov.: (6) holótipo macho; (7) alótipo; (8-9) Actinote mielkei sp. nov.: (8) holótipo macho; (9) alótipo; (10) Actinote furtadoi sp. nov., holótipo macho; (11) Actinote morio beckeri ssp. nov.: holótipo macho; (12-13) Actinote pellenea giffordi ssp. nov.: (12) holótipo macho; (13) alótipo. (D) Dorsal, (V) ventral.

ambas alaranjadas. Membrana da área costal ocupada apenas por cerdas após o término da faixa.

Face dorsal da asa posterior: faixa marginal estreita com a metade da largura do tórax - medida em $\mathrm{M}_{2}$, venais inconspícuas, intervenais e intradiscal bem marcadas e castanhas. Mancha discal inconspícua. Entre a margem interna e 3A, a membrana apresenta escamas alaranjadas mescladas com amarelas, restante da asa preenchido por castanho alaranjado.
Face ventral da asa anterior: mesmo padrão da face dorsal, porém mais clara e com mais escamas. Fundo, faixas venais e intervenais castanho claro, intercaladas por prolongamentos amarelos esbranquiçados da faixa subapical e manchas marginais 1 e 2. Faixas costal e subcostal formadas por escamas amarelas, inseridas espaçadamente por toda a membrana, porém a área costal, após a célula discal, apresenta apenas cerdas.

Face ventral da asa posterior: faixas venais inconspícuas,

Revista Brasileira de Zoologia 23 (3): 764-778, setembro, 2006 


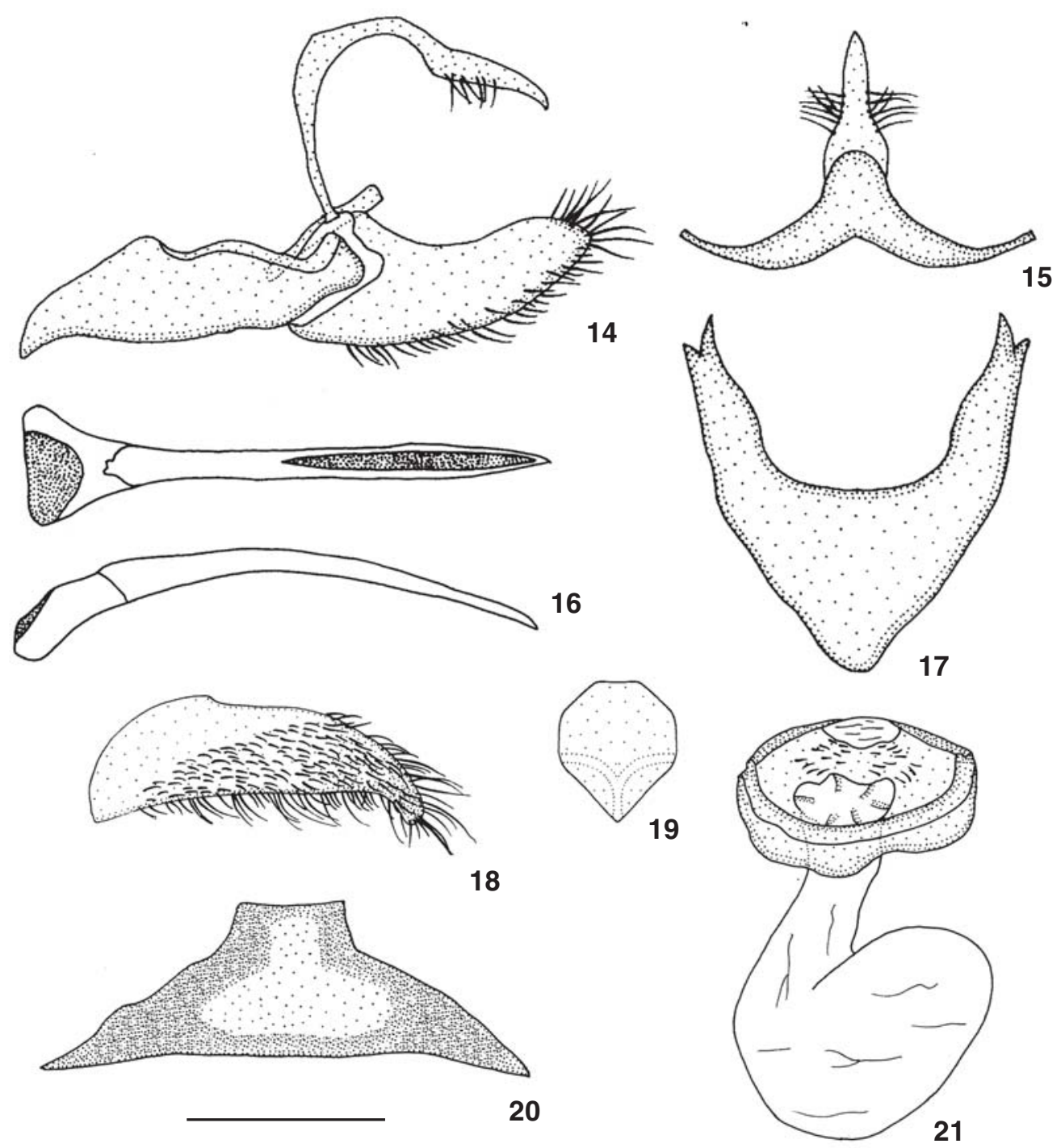

Figuras 14-21. Actinote mirnae sp. nov., genitália masculina e oitavo esterno (DZ 6335) e feminina (DZ 6439): (14) vista lateral do tegume, unco, saco, juxta e valva; (15) vista dorsal do tegume e unco; (16) vistas dorsal e lateral do edeago; (17) vista ventral do saco; (18) vista ventral da valva; (19) vista ventral da juxta; (20) vista ventral do oitavo esterno; (21) vista ventral do esterigma e bolsa copuladora. Escala: $1 \mathrm{~mm}$.

intervenais e intradiscal bem marcadas, castanho claro. Mancha discal um pouco mais clara, levemente pontuda após a célula discal entre $\mathrm{Sc}+\mathrm{R}_{1}$ e $\mathrm{CuA}_{2}$. Restante da membrana alar amarelo claro esbranquiçado. Cerdas intradiscais presentes.

Genitália masculina (Figs 14-20). Tegume com os braços em forma de barras estreitas. Unco simples separado do tegume por sutura, no bordo dorso-lateral basal um aglomerado de cerdas, lateralmente com porção distal curva, comprimento tegume+unco pouco menor que o da valva. Gnato ausente. Saco com projeção anterior em forma de triângulo isósceles, mais longo do que alto e com uma crista proeminente no bordo superior do braço. Valva cilindro-cônica, cerdosa, com o ápice cônico, em vista ventral levemente curvada para dentro, comprimento um pouco menor que o total do saco, porém com altura similar. Juxta laminar, suboctogonal, com crista em " $\mathrm{Y}$ " na face dorsal. Edeago com a porção anterior de forma triangular, corpo com diâmetro menor e uniforme, comprimento total similar ao do saco + valva, em vista lateral levemente curvo. Oitavo esterno subtrapezoidal.

Fêmea (Fig. 7), asa anterior $(\mathrm{n}=9)$ : comprimento da margem costal - 33 a $40 \mathrm{~mm}$; margem externa - 19,5 a 23,5 $\mathrm{mm}$; largura da asa -19 a $22,5 \mathrm{~mm}$. Asa posterior $(\mathrm{n}=9)$ : comprimento da margem costal - 23,5 a $27 \mathrm{~mm}$; margem externa 17 a $20 \mathrm{~mm}$; maior comprimento da asa -25 a $29 \mathrm{~mm}$.

Revista Brasileira de Zoologia 23 (3): 764-778, setembro, 2006 
Faces dorsal e ventral da asa anterior: difere do macho por apresentar a faixa subapical variando do amarelo claro esbranquiçado ao alaranjado claro.

Faces dorsal e ventral da asa posterior: difere do macho por apresentar variações do amarelo claro esbranquiçado ao castanho alaranjado na face dorsal, além da faixa marginal mais larga, medida em $\mathrm{M}_{2}$ igual ou pouco maior que a do tórax.

Genitália feminina (Fig. 21). Esterigma elipsóide, constituído pela lamela ante-vaginal, reforçada por bordo posterior esclerotinizado que circunda posteriormente a lamela pós-vaginal, essa possui um aglomerado de microcerdas inseridas acima do óstio. Bolsa copuladora reduzida, sem signos, conectada diretamente ao óstio da bolsa, circular, abre-se diretamente ao exterior.

Tampão genital retângulo cônico, com o ápice em contato com o sexto e recobrindo totalmente o sétimo esterno do abdome feminino, que apresenta uma ligação relativamente uniforme entre o sétimo esterno e o esterigma (РALuch et al. 2003).

Material estudado. Holótipo macho com as seguintes etiquetas:/Holotypus/22-24.X.1983, Chulumani - Bolívia, 1400m, Mielke \& Casagrande leg./Holotypus Actinote mirnae Paluch \& Mielke, det. 2006/DZ 6311/. Alótipo com as seguintes etiquetas:/Allotypus/22-24.X.1983, Chulumani - Bolívia, 1400m, Mielke \& Casagrande leg./Allotypus Actinote mirnae Paluch \& Mielke, det. 2006/DZ 6415/ambos DZUP.

Parátipos. Bolívia: Chulumani, 1400 m, 1 macho e 8 fêmeas, 22-24.X.1983, Mielke \& Casagrande leg., DZ 6335, DZ 6439, DZ 6343, DZ 6303, DZ 6327, DZ 6367, DZ 6455, DZ 4772, DZ 6359 (DZUP). PERU, Tingo Maria, 1 macho [sem abdome], 1.XI.1949, H.A. Allard leg. (MHNL).

Etimologia. Espécie dedicada a Dra. Mirna Martins Casagrande, um dos coletores da série tipo.

Observações: Apesar de alopátrica, o padrão geral das asas é muito similar ao de $A$. genitrix $\mathrm{D}^{\prime}$ Almeida, 1922, porém as cerdas intradiscais estão presentes em $A$. mirnae e as faixas venais são mais estreitas que as intervenais, ao contrário de $A$. genitrix; contudo as genitálias masculina e feminina são extremamente distintas e corroboram a caracterização da espécie.

\section{Actinote mielkei Paluch \& Casagrande, sp. nov. Figs 8-9, 22-28}

Diagnose. Asa anterior com fundo castanho; faixa subapical estreita e amarelo esbranquiçada, faixa subdiscal dividida longitudinalmente por linha estreita e castanha. Asa posterior com faixas marginal com largura igual a do tórax, venais estreitas em ambas as faces, intervenais curtas e intradiscal inconspícua dorsalmente; mancha discal sutilmente pontuada após a célula discal em ambas as faces; cerdas intradiscais ausentes.

Descrição. Macho, (Fig. 8) asa anterior (n = 2): comprimento da margem costal - 35 a $39 \mathrm{~mm}$; margem externa - 21 a $22 \mathrm{~mm}$; largura da asa $-20,5$ a $21,5 \mathrm{~mm}$. Asa posterior $(\mathrm{n}=2)$ : comprimento da margem costal - 25 a $27 \mathrm{~mm}$; margem externa - 19 a $21 \mathrm{~mm}$; maior comprimento da asa -26 a $28 \mathrm{~mm}$.
Face dorsal da asa anterior: castanha com faixa subapical amarelo esbranquiçada, mais estreita que $A$. thalia crassinia (Hopffer, 1874), subespécie simpátrica com o mesmo padrão de coloração; faixas intradiscal basal-distal, subdiscal e as manchas subdiscal e marginal 2, alaranjado claras, faixa subdiscal dividida longitudinalmente por uma linha estreita e castanha semelhante à Actinote quadra (Schaus, 1902). Faixa costal com comprimento igual à largura do olho, subcostal apresenta a metade do comprimento da faixa intradiscal basal, ambas alaranjadas. Membrana da área costal ocupada por escamas bífidas e trífidas, afiladas na metade proximal a margem costal, que também apresenta cerdas distribuídas longitudinalmente.

Face dorsal da asa posterior: faixa marginal estreita, medida em $\mathrm{M}_{2}$, com a largura igual ao tórax, venais estreitas, intervenais curtas e intradiscal inconspícua, castanhas. Mancha discal sutilmente pontuada de castanho claro, após a célula discal. Entre 2A e a margem interna, a membrana apresenta escamas amarelas, restante da asa preenchido por alaranjado claro.

Face ventral da asa anterior: mesmo padrão geral da face dorsal, porém mais claro. Faixa pós-discal vestigial, marginal interna ocupando toda a área membranosa, ambas alaranjadas. Fundo, faixas venais e intervenais castanho claras, intercaladas com os prolongamentos ocráceos da faixa subapical e manchas marginais 1 e 2 . Faixas costal e subcostal ocupam toda área membranosa, a porção basal apresenta escamas amarelas mescladas com alaranjadas inseridas espaçadamente, e as porções mediana e distal, amarelo, área costal com cerdas apenas no ápice.

Face ventral da asa posterior: faixas venais, intervenais longas e intradiscal, castanho claro. Mancha discal pouco mais clara, levemente pontuda após a célula discal entre $\mathrm{Sc}+\mathrm{R}_{1}$ e $\mathrm{CuA}_{2}$; restante da membrana alar amarelo claro; cerdas intradiscais ausentes.

Genitália masculina (Figs 22-28). Tegume com braços estreitos. Unco simples separado do tegume por uma sutura, no bordo dorso-lateral basal e mediano ocorre um aglomerado de cerdas, lateralmente com porção distal curva, comprimento tegume+unco igual a $2 / 3$ da valva. Gnato ausente. Saco com projeção anterior em forma de triângulo eqüilátero, mais longo do que alto com uma crista proeminente no bordo superior do braço. Valva cilindro-cônica, cerdosa, relativamente reta, com o ápice afilado, em vista ventral abruptamente curvada para dentro, comprimento um pouco maior que o total do saco, porém com altura similar. Juxta laminar, com base superior reta com estrangulamento na porção mediana e afilamento na porção inferior, apresentando a forma geral de um pião, com crista em " $Y$ " na face dorsal. Edeago com a porção anterior globosa abruptamente afilada em um "gargalo", cujo diâmetro segue constante com o restante do corpo, afilando na porção distal; comprimento total um pouco menor que o do saco + valva; em vista lateral apresenta-se reto. Oitavo esterno trapezoidal, lobado na base lateralmente.

Fêmea (Fig. 9), asa anterior $(n=1)$ : comprimento da margem costal - $42 \mathrm{~mm}$; margem externa $-24 \mathrm{~mm}$; largura da asa $-23,5 \mathrm{~mm}$. Asa posterior $(\mathrm{n}=1)$ : comprimento da margem 

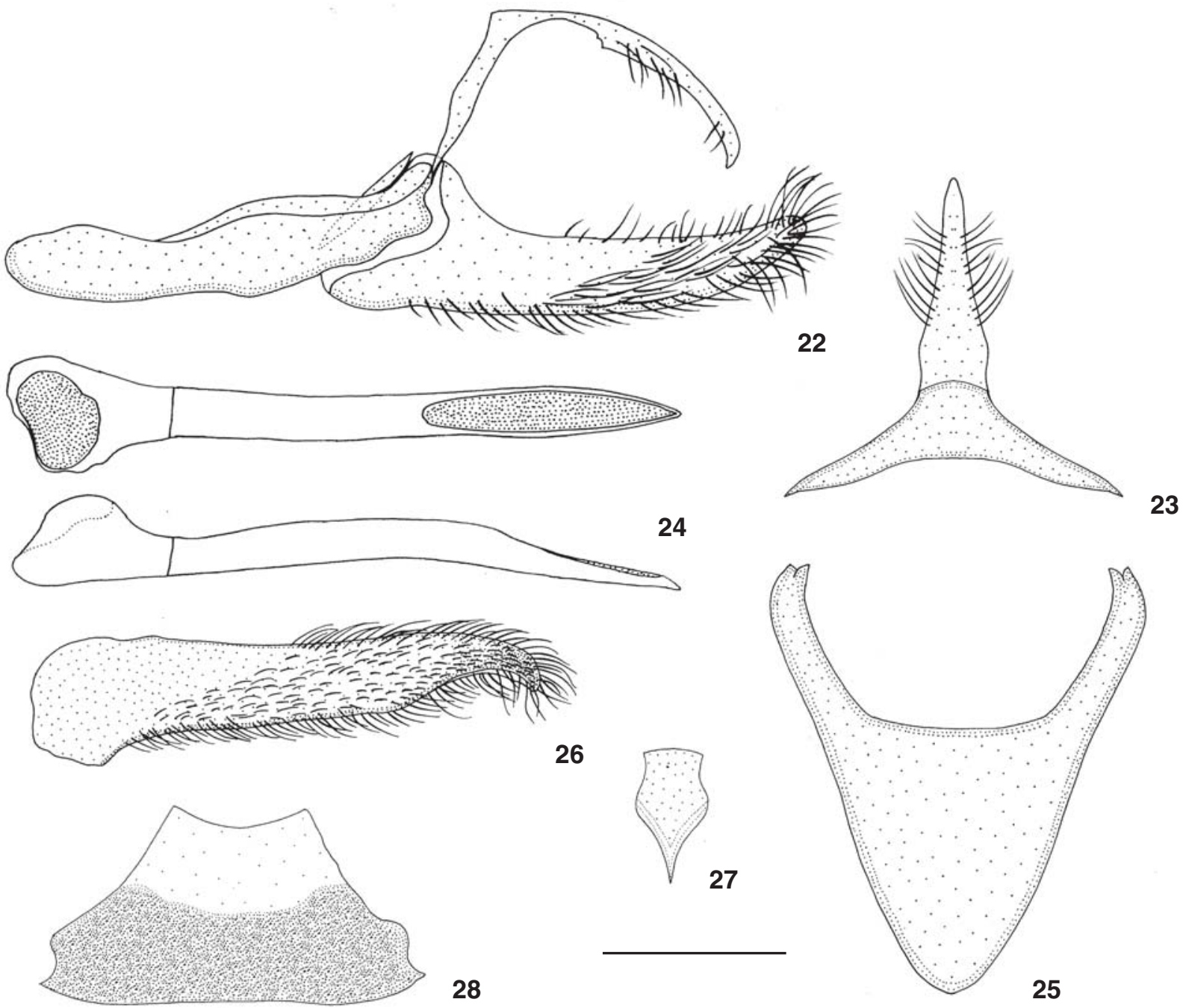

26

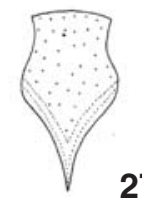

28

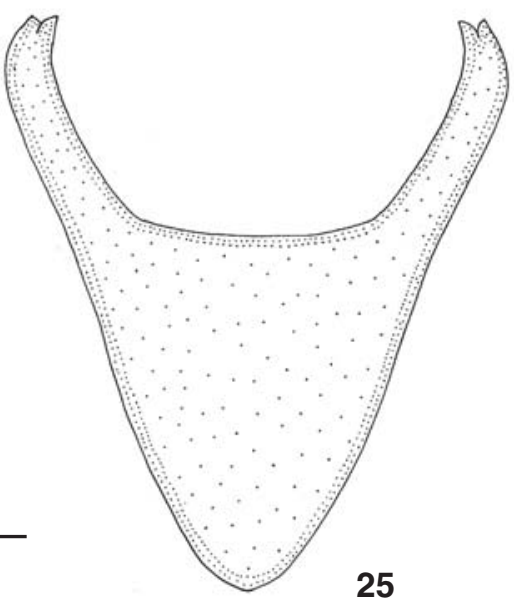

Figuras 22-28. Actinote mielkei sp. nov., genitália masculina e oitavo esterno (DZ 6381): (22) vista lateral do tegume, unco, saco, juxta e valva; (23) vista dorsal do tegume e unco; (24) vistas dorsal e lateral do edeago; (25) vista ventral do saco; (26) vista ventral da valva; (27) vista ventral da juxta; (28) vista ventral do oitavo esterno. Escala: $1 \mathrm{~mm}$.

costal - $28 \mathrm{~mm}$; margem externa - $22 \mathrm{~mm}$; maior comprimento da asa $-29 \mathrm{~mm}$.

Faces dorsal e ventral da asa anterior: difere do macho por apresentar a faixa subapical mais larga, além das faixas intradiscal basal-distal, subdiscal e a mancha subdiscal menos escamas de aspecto translúcido.

Faces dorsal e ventral da asa posterior: mesmo padrão de ornamentação e coloração da asa do macho, pouco mais clara.

Genitália feminina. Não analisada.

Tampão genital triangular, com o ápice em contato parcial com o sétimo esterno do abdome feminino, conectado verticalmente ao esterigma que apresenta uma ligação abrupta em "degrau" formado pela lamela ante-vaginal (PALuCH et al. 2003).

Material estudado. Holótipo macho com as seguintes eti-
quetas:/Holotypus/22-24.X.1983, Chulumani - Bolívia, 1400m, Mielke \& Casagrande leg./Holotypus Actinote mielkei Paluch \& Casagrande, det. 2006/DZ 6389/Alótipo com as seguintes etiquetas:/Allotypus/22-24.X.1983, Chulumani - Bolívia, 1400m, Mielke \& Casagrande leg./Allotypus Actinote mielkei Paluch \& Casagrande, det. 2006/DZ 6221/ambos DZUP.

Parátipo. Bolívia: Chulumani, 1400 m, 1 macho, 22-24.X. 1983, Mielke \& Casagrande leg., DZ 6381 (DZUP).

Etimologia. Espécie dedicada ao Dr. Olaf Hermann Hendrik Mielke, um dos coletores da série tipo.

Observações: Similar a A. thalia crassinia, subespécie simpátrica; porém a faixa subdiscal é dividida longitudinalmente por uma linha estreita e castanha. A genitália masculina é distinta e corrobora a caracterização da espécie.

Revista Brasileira de Zoologia 23 (3): 764-778, setembro, 2006 


\section{Actinote furtadoi \\ Paluch, Casagrande \& Mielke, sp. nov. Figs 10, 29-36}

Diagnose. Asa anterior com fundo castanho escuro; faixa subapical amarela, faixas intradiscal basal-distal, subdiscal, e as manchas subdiscal e marginal 2, alaranjadas. Asa posterior com faixa marginal com largura um pouco maior que o tórax, intervenais muito curtas visíveis junto à faixa marginal, intradiscal inconspícua; mancha discal inconspícua dorsalmente; cerdas intradiscais ausentes. Veias $\mathrm{R}_{\mathrm{s}}$ e $\mathrm{M}_{1}$ se anastomosam em uma única veia que se projeta a partir da célula discal, bifurcando próxima a mancha discal.

Descrição. Macho (Fig. 10), asa anterior ( $\mathrm{n}=7)$ : comprimento da margem costal - 28 a $33 \mathrm{~mm}$; margem externa - 16 a $20 \mathrm{~mm}$; largura da asa $-15,5$ a $19,5 \mathrm{~mm}$. Asa posterior $(\mathrm{n}=7)$ : comprimento da margem costal - 19,5 a 24,5 mm; margem externa - 14 a 17,5 mm; maior comprimento da asa - 18,5 a $23 \mathrm{~mm}$.

Face dorsal da asa anterior: castanho escuro, faixa subapical amarela, faixas intradiscal basal-distal, subdiscal, marginal interna vestigial e as manchas subdiscal e marginais 1 (vestigial ou ausente) e 2, alaranjadas. Faixas costal vestigial e subcostal com o mesmo comprimento da faixa intradiscal basal, ambas alaranjadas. Membrana da área costal ocupada apenas por escamas.

Face dorsal da asa posterior: faixa marginal com largura, medida em $M_{2}$, pouco maior que o tórax, venais estreitas, intervenais muito curtas visíveis junto à faixa marginal, castanho escuras, intradiscal inconspícua. Mancha discal inconspícua. Entre $2 \mathrm{~A}$ e a margem interna, a membrana apresenta escamas alaranjadas, mescladas com amarelas, restante da asa preenchido por alaranjado médio.

Face ventral da asa anterior: faixa subapical amarelo clara; faixas intradiscal basal-distal, subdiscal, e as manchas subdiscal e marginal 2, alaranjado claras. A faixa marginal interna amarela acompanha a faixa subdiscal. Fundo, faixas venais e intervenais castanhos, intercaladas com prolongamentos amarelos mesclados com alaranjado da faixa subapical e das manchas marginais 1 e 2 . Faixas costal e subcostal ocupam toda área membranosa, a porção basal apresenta escamas alaranjadas inseridas espaçadamente, e as porções mediana e distal, amarelo; área costal com cerdas apenas no ápice.

Face ventral da asa posterior: faixas venais, intervenais e intradiscal castanhas. Mancha discal pouco mais clara e levemente afilada após a célula discal entre $\mathrm{Sc}+\mathrm{R}_{1}$ e $\mathrm{CuA}$; restante da membrana alar amarelo mesclada com alaranjado claro; cerdas intradiscais ausentes.

Genitália masculina (Figs 29-35). Tegume expandido nos braços, em forma de barra triangular. Unco simples, separado do tegume por uma sutura, no bordo dorso-lateral basal e mediano um aglomerado de cerdas, lateralmente com porção distal curva, comprimento tegume+unco similar ao da valva. Gnato ausente. Saco com projeção anterior reduzida, braços largos, ven- tralmente com forma geral de um "V", mais longo do que alto e com uma crista proeminente no bordo superior do braço, este curvado abruptamente na porção distal. Valva cilindro-cônica, cerdosa, curvada em direção ao unco, ápice quadrangular, em vista ventral levemente voltada para dentro; comprimento pouco menor que o total do saco, porém com altura similar. Juxta laminar, com base superior côncava, laterais abauladas na porção mediana e afilamento na porção inferior apresentando a forma geral hexagonal, com crista em " $\mathrm{Y}$ " na face dorsal. Edeago com porção anterior retangular afilando posteriormente, cujo diâmetro segue constante com o restante do corpo, seu comprimento total é pouco menor que a somatória do saco e valva; em vista lateral levemente curvo. Oitavo esterno retangular e de porção mediana superior ressaltada.

Fêmea, asa anterior $(\mathrm{n}=1)$ : comprimento da margem costal - 35,5 mm; margem externa - $20 \mathrm{~mm}$; largura da asa $19,5 \mathrm{~mm}$. Asa posterior $(\mathrm{n}=1)$ : comprimento da margem costal - $25 \mathrm{~mm}$; margem externa - 18,5 $\mathrm{mm}$; maior comprimento da asa $-26,5 \mathrm{~mm}$.

Apresenta o mesmo padrão de ornamentação e coloração das asas do macho, porém um pouco mais clara.

Genitália feminina (Fig. 36). Esterigma trapezoidal, constituído de lamela ante-vaginal côncava que forma uma aba cobrindo parcialmente o óstio da bolsa, lamela pós-vaginal triangular. Bolsa copuladora reduzida e sem signos, conectada diretamente ao óstio da bolsa circular e abre-se diretamente ao exterior.

Material estudado. Holótipo macho com as seguintes etiquetas:/Holotypus/6.XII.1975, Alto Rio Arinos, Faz. S. João, Diamantino, MT, [Brasil], Furtado leg./Holotypus Actinote furtadoi Paluch, Casagrande \& Mielke, det. 2006/DZ 9300/. Alótipo com as seguintes etiquetas:/Allotypus/20.II.1977, Alto Rio Arinos, Faz. S. João, Diamantino, MT, [Brasil], Furtado leg./ Allotypus Actinote furtadoi Paluch, Casagrande \& Mielke, det. 2006/DZ 9363/Genitália Preparada, M. Paluch 2003/; ambos DZUP.

Parátipos. Brasil, Mato Grosso: Diamantino, Alto Rio Arinos, Fazenda São João, 300-400m, 3 machos, 6.XII.1975, 1 macho, 26.V.1976, 1 macho, 15.XI.1977, E. Furtado leg. DZ 9467, DZ 9435, DZ 9203, DZ 9397, DZ 2971 (DZUP). Bolívia: Yungas de la Paz, 1850 m, 1 macho, IX.1956, Foerster leg. DZ 9227 (DZUP).

Etimologia. Espécie dedicada ao Sr. Eurides Furtado, coletor dos espécimes brasileiros da série tipo.

Observações. A. furtadoi, apresenta similaridade na coloração das asas com $A$. thalia crassinia com distribuição no Peru e Bolívia e com A. thalia eupelia Jordan, 1913 com populações distribuídas na Argentina e Sul da Bolívia; apesar da genitália se aproximar com as subespécies de $A$. thalia (Linnaeus, 1758), as veias $R_{\mathrm{s}}$ e $\mathrm{M}_{1}$ da asa posterior se anastomosam em uma única que se alonga a partir da célula discal; sendo que todas as subespécies de $A$. thalia apresentam essas veias separadas pela veia dcs. 

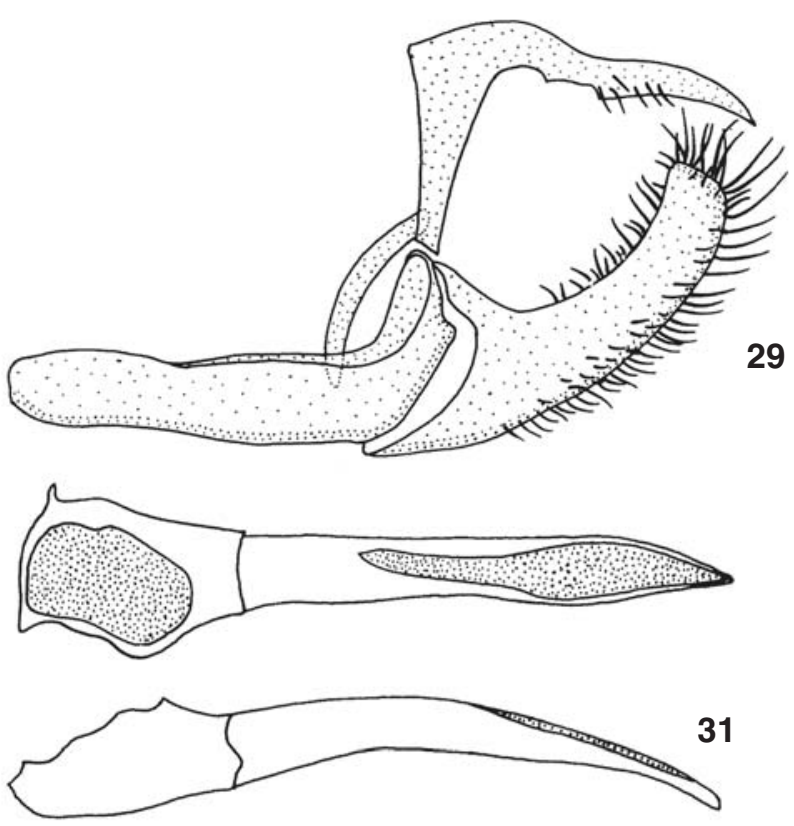

31

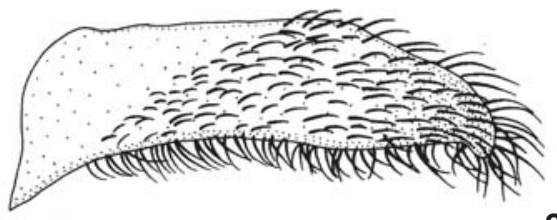

33
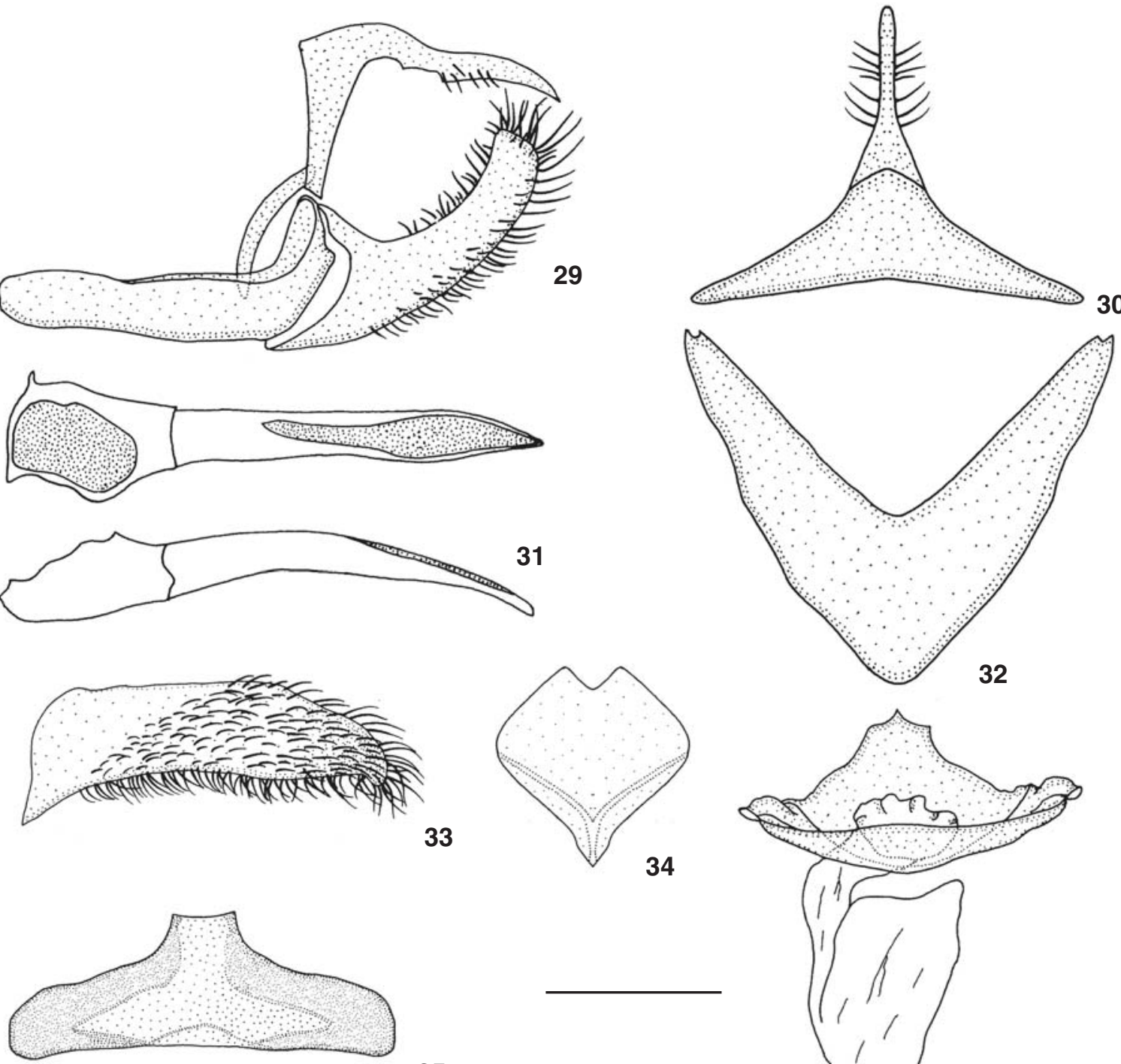

35

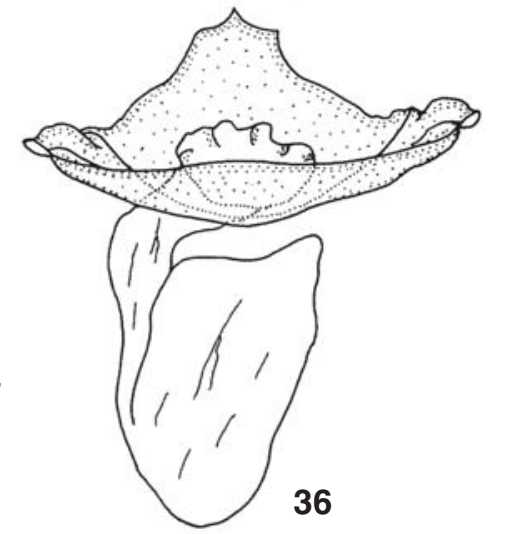

Figuras 29-36. Actinote furtadoi sp. nov., genitália masculina e oitavo esterno (DZ 9467) e feminina (DZ 9363): (29) vista lateral do tegume, unco, saco, juxta e valva; (30) vista dorsal do tegume e unco; (31) vistas dorsal e lateral do edeago; (32) vista ventral do saco; (33) vista ventral da valva; (34) vista ventral da juxta; (35) vista ventral do oitavo esterno; (36) vista ventral do esterigma e bolsa copuladora. Escala: $1 \mathrm{~mm}$.

\section{Actinote morio beckeri Paluch, Casagrande \& Mielke, ssp. nov.}

\section{Figs 11, 37-43}

Diagnose. Asa anterior com fundo castanho escuro; faixas subapical, intradiscal distal quadrangular e manchas marginais 1 e 2 vestigiais, amarelo esbranquiçadas. Asa posterior em face dorsal com faixa marginal nitidamente marcada com largura igual a do tórax, faixas venais largas, intervenais largas e longas, intradiscal dupla, castanho escuras. Mancha discal ausente em ambas as faces, dorsalmente entre $2 \mathrm{~A}$ e a margem interna a membrana apresenta escamas amarelas, restante do preenchimento alar entre as faixas, castanho alaranjado; cerdas intradiscais presentes.

Descrição. Macho (Fig. 11), asa anterior ( $\mathrm{n}=2$ /similares): comprimento da margem costal $-33 \mathrm{~mm}$; margem externa $-19,5 \mathrm{~mm}$; largura da asa $-19 \mathrm{~mm}$. Asa posterior $(\mathrm{n}=2$ / similares): comprimento da margem costal $-21 \mathrm{~mm}$; margem externa - $17 \mathrm{~mm}$; maior comprimento da asa $-22 \mathrm{~mm}$.

Revista Brasileira de Zoologia 23 (3): 764-778, setembro, 2006 

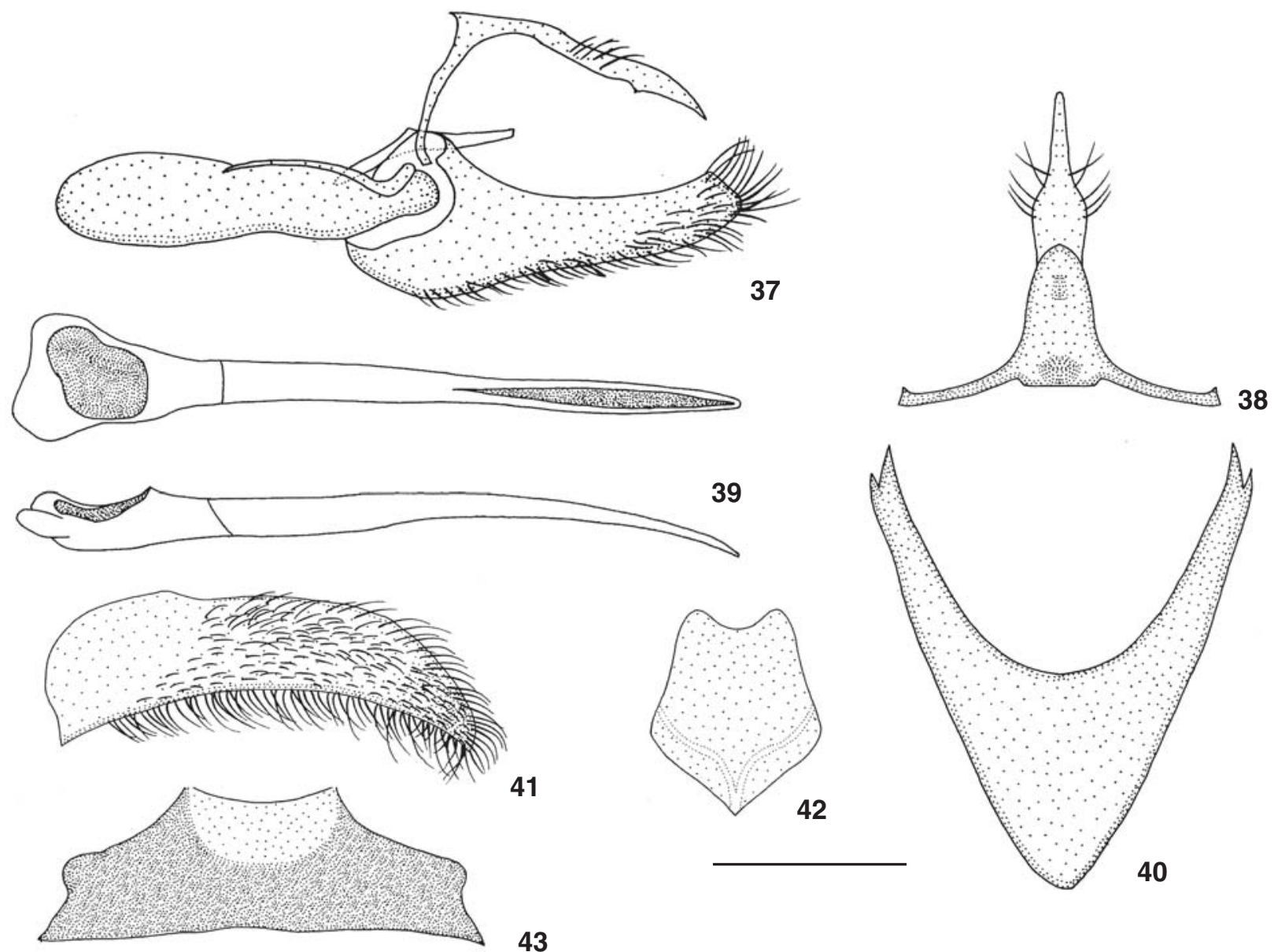

\section{3}

Figuras 37-43. Actinote morio beckeri ssp. nov., genitália masculina e oitavo esterno (CPAC n 8945): (37) vista lateral do tegume, unco, saco, juxta e valva; (38) vista dorsal do tegume e unco; (39) vistas dorsal e lateral do edeago; (40) vista ventral do saco; (41) vista ventral da valva; (42) vista ventral da juxta; (43) vista ventral do oitavo esterno. Escala: $1 \mathrm{~mm}$.

Face dorsal da asa anterior: fundo castanho escuro; faixa subapical, intradiscal distal quadrangular e as manchas marginais 1 e 2 vestigiais, amarelo esbranquiçadas; faixas intradiscal basal, subdiscal e a mancha subdiscal estão ausentes, áreas translúcidas escamadas. Faixa costal ausente, subcostal amarela com comprimento igual a largura do olho. Membrana da área costal ocupada por cerdas na metade proximal a margem costal.

Face dorsal da asa posterior: ao contrário de Actinote morio morio Oberthür, 1917, todas as faixas são conspícuas e destacadas. Faixa marginal, medida em $\mathrm{M}_{2}$ com largura igual a do tórax, venais largas, intervenais largas e longas e intradiscal dupla sendo a linha superior menor e mais fina, castanho escuras. Mancha discal ausente. Entre a margem interna e as veias $3 \mathrm{~A}$ e $2 \mathrm{~A}$ a membrana apresenta escamas amarelas, restante da asa preenchido por castanho alaranjado.

Face ventral da asa anterior: mesmo padrão geral da face dorsal, porém mais claro. Faixas intradiscal basal, subdiscal e, mancha subdiscal com poucas escamas amarelas. Fundo, faixas venais e intervenais castanhas, intercaladas pelos prolongamentos amarelos da faixa subapical e manchas marginais 1 e 2 . Faixas costal e subcostal ocupam toda área membranosa com escamas amarelas inseridas espaçadamente, porém a área costal após a célula discal apresenta apenas cerdas inseridas na membrana.

Face ventral da asa posterior: faixas venais, intervenais largas e intradiscal dupla, castanhas. Mancha discal ausente. Restante da membrana alar é amarelo claro. Cerdas intradiscais presentes.

Genitália masculina (Figs 37-43). Tegume com braços estreitos, em vista dorsal apresenta duas "áreas circulares", uma anterior e outra posterior, finamente esclerotinizadas e de aspecto membranoso. Unco simples separado do tegume por sutura, no bordo dorso-lateral basal e mediano um aglomerado de cerdas, comprimento tegume+unco pouco menor que o da valva. Gnato ausente. Saco com projeção anterior em forma de 
um triângulo isósceles, mais longo do que alto e com crista proeminente no bordo superior do braço. Valva cilindro-cônica, cerdosa, com a porção basal alargada, ápice quadrangular, ventralmente curvo para dentro, comprimento similar ao total do saco. Juxta laminar, com base superior côncava, laterais abauladas na porção mediana, sendo a porção inferior triangular, com crista em " $Y$ " na face dorsal. Edeago com a porção anterior retangular e bilobada, com estrangulamento posterior, de diâmetro constante e o restante do corpo afilando na porção distal, comprimento total um pouco maior que o do saco + valva, em vista lateral levemente curvo na porção distal. Oitavo esterno trapezoidal, lobado lateralmente na porção mediana.

Material estudado. Holótipo macho com as seguintes etiquetas:/Holotypus $/ 1^{\circ} 35^{\prime} \mathrm{S}, 4^{\circ} 42^{\prime} \mathrm{W}$, Planaltina, DF, Brasil 1000m, 20.XII.1976, V.O. Becker col./Coleção EMBRAPA-CPAC $\mathrm{n}^{\circ} 3319$ [doado ao DZUP]/Holotypus Actinote morio beckeri Paluch, Casagrande \& Mielke, det. 2006/DZ 9335/.

Parátipo. BRasiL, Distrito Federal: Planaltina, 1000 m, 15³5'S, $47^{\circ} 42^{\prime}$ W, 1 macho, 18.IV.1942, V.O. Becker leg. no 8945 (CPAC).

Etimologia. Subespécie dedicada ao Dr. Vitor Osmar Becker, coletor dos dois espécimes conhecidos.

Observações: Actinote morio morio, faz parte da lista oficial da fauna ameaçada de extinção do estado de Minas Gerais (MIELKE et al. 1997), essa subespécie está restrita a Serra da Mantiqueira (850-1400m), Minas Gerais, sendo que em 5-8.XII.2002, o início da revoada de uma população foi observada por Olaf H.H. Mielke na Unidade Ambiental de Peti, São Gonçalo do Rio Abaixo, Minas Gerais (560 m), sendo esse o registro mais recente da subespécie, que pode viabilizar estudos biológicos mais detalhados sobre essa população.

Actinote morio beckeri, conhecida a partir de dois machos muito similares de Planaltina, Distrito Federal, sugere uma distribuição pela província biogeográfica do Cerrado brasileiro; difere de Actinote morio morio principalmente por apresentar na asa posterior em face dorsal, a faixa marginal nitidamente marcada com largura igual a do tórax, faixas venais largas, intervenais largas e longas, intradiscal dupla. Preenchimento alar entre as faixas, castanho alaranjado.

\section{Actinote pellenea giffordi Paluch, Casagrande \& Mielke, ssp. nov. Figs 12-13, 44-51}

Diagnose. Asa anterior com fundo castanho escuro; faixa subapical amarela, faixas intradiscal basal-distal, subdiscal estreita e mancha subdiscal com poucas escamas, amarelo ocráceo claras. Asa posterior com faixas marginal com largura igual a do tórax, venais, intervenais longas e largas e intradiscal, castanho escuras; mancha discal inconspícua dorsalmente e marcada ventralmente após a célula discal entre $\mathrm{Sc}+\mathrm{R}_{1}$ e $\mathrm{CuA}_{2}$, formando um borrão entre as veias $\mathrm{R}_{\mathrm{s}}$.e $\mathrm{CuA}_{1}$; cerdas intradiscais presentes.

Descrição. Macho (Fig. 12), asa anterior $(n=4)$ : comprimento da margem costal - 26 a $28 \mathrm{~mm}$; margem externa - 15 a
15,5 mm; largura da asa $-14,5$ a $15 \mathrm{~mm}$. Asa posterior $(\mathrm{n}=4)$ : comprimento da margem costal - 18 a 18,5 mm; margem externa -13 a 13,5 mm; maior comprimento da asa $-18,5$ a $19 \mathrm{~mm}$.

Face dorsal da asa anterior: fundo castanho escuro; faixa subapical amarela, faixas intradiscal basal-distal, amarelo ocráceo claras, faixa e mancha subdiscais com poucas escamas e da mesma coloração. Faixa costal vestigial, subcostal com a metade do comprimento da faixa intradiscal basal, ambas ocráceas. Membrana da área costal ocupada por cerdas próximas a margem e escamas na metade proximal da Sc.

Face dorsal da asa posterior: faixa marginal com largura, medida em $\mathrm{M}_{2}$ igual a do tórax, venais, intervenais longas e largas e intradiscal, castanho escuras. Mancha discal inconspícua. Entre $2 \mathrm{~A}$ e a margem interna, membrana apresenta escamas amarelas, mescladas com ocre e o restante da asa preenchido por amarelo ocráceo.

Face ventral da asa anterior: mesmo padrão geral da face dorsal, porém mais claro. Fundo, faixas venais e intervenais castanho, intercaladas com os prolongamentos ocráceos da faixa subapical e manchas marginais 1 e 2 . Faixas costal e subcostal ocupam toda área membranosa com escamas amarelas inseridas espaçadamente, porém a área costal após a célula discal apresenta apenas cerdas inseridas na membrana.

Face ventral da asa posterior: faixas venais, intervenais largas e longas e intradiscal, castanhas. Mancha discal pouco mais clara, marcada após a célula discal entre $\mathrm{Sc}+\mathrm{R}_{1}$ e $\mathrm{CuA}_{2}$, formando um borrão entre as veias $\mathrm{R}_{\mathrm{s}} \mathrm{e} \mathrm{CuA_{1 }}$. Restante da membrana alar amarelo claro. Cerdas intradiscais presentes.

Genitália masculina (Figs 44-50). Tegume com braços estreitos. Unco em vista lateral com a porção distal curvada. Saco com projeção anterior em forma de triângulo isósceles, mais longo que alto e com uma crista proeminente no bordo superior do braço. Valva cilindro-cônica, cerdosa, alargada desde a base, com o ápice quadrangular, em vista ventral levemente curva para dentro, seu comprimento e altura são pouco maiores que as do saco. Juxta laminar com base superior côncava, laterais abauladas e afiladas na porção inferior de aspecto cordiforme; crista em "Y" não diagnosticada. Edeago com a porção anterior quadrangular, com projeções em forma de acúleos na porção mediana lateral ( $\mathrm{n}=1$ com possível variação intraespecífica), estrangulamento posterior, cujo diâmetro segue constante com o restante do corpo afilando na porção distal; em vista lateral levemente curvo. Oitavo esterno trapezoidal, com um leve estrangulamento na porção superior e lateral.

Fêmea (Fig. 13), asa anterior $(\mathrm{n}=3)$ : comprimento da margem costal $-27,5$ a $30 \mathrm{~mm}$; margem externa -15 a $16 \mathrm{~mm}$; largura da asa $-14,5$ a $15,5 \mathrm{~mm}$. Asa posterior $(\mathrm{n}=3)$ : comprimento da margem costal - 20 a 21,5 mm; margem externa - 14 a $15 \mathrm{~mm}$; maior comprimento da asa $-19,5$ a $22 \mathrm{~mm}$.

Face dorsal da asa anterior: difere do macho por apresentar faixas intradiscal basal e distal, vestigiais e amarelo claras, faixa e mancha subdiscais ausentes em área translúcida. Faixas costal ausente e subcostal vestigial amarela. 

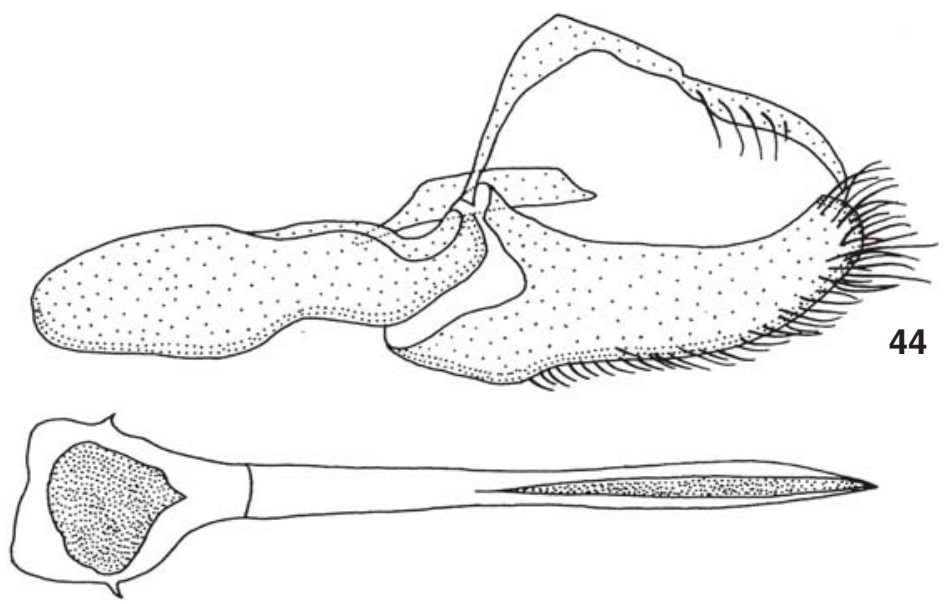

46
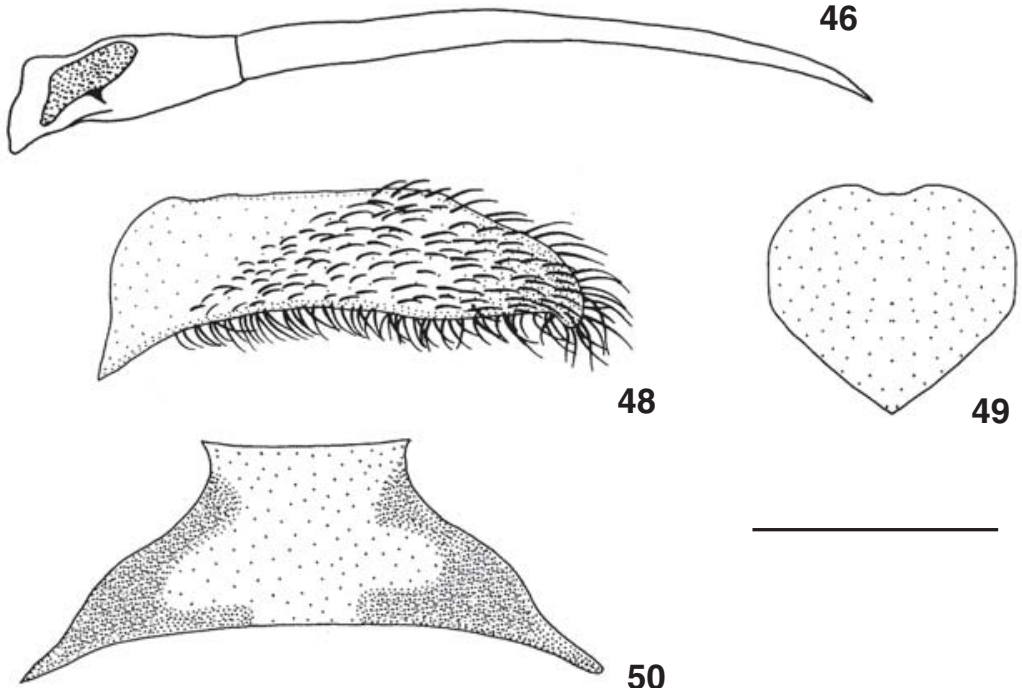

48

49

50
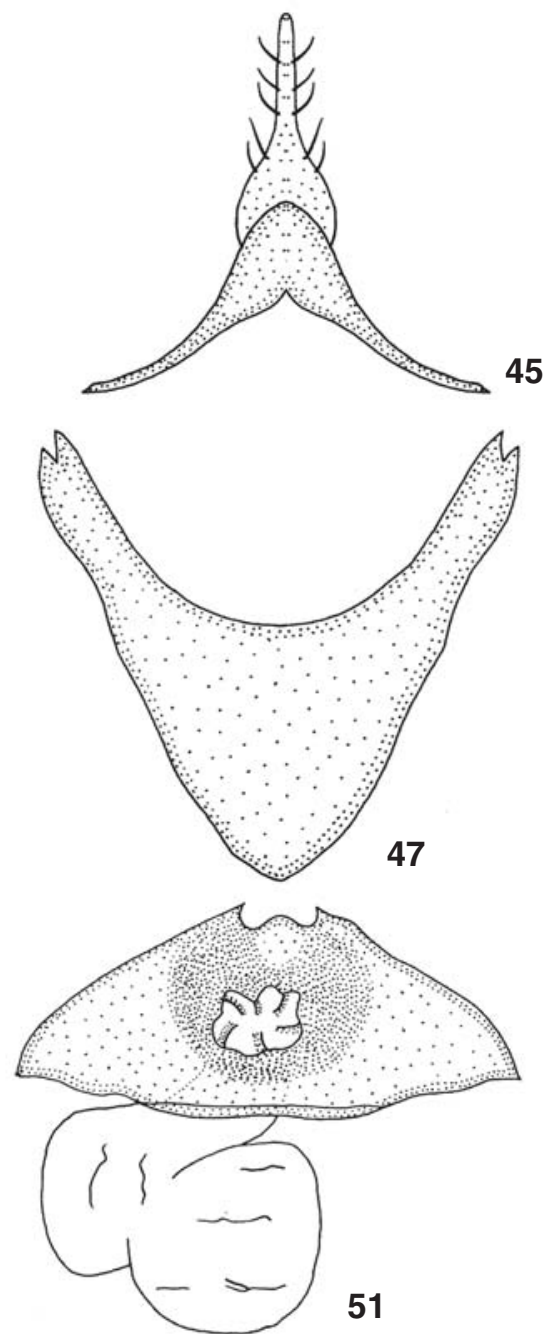

Figuras 44-51. Actinote pellenea giffordi ssp. nov., genitália masculina e oitavo esterno (DZ 6775) e feminina (CPAC $\mathrm{n}^{\circ}$ 12108): (44) vista lateral do tegume, unco, saco, juxta e valva; (45) vista dorsal do tegume e unco; (46) vistas dorsal e lateral do edeago; (47) vista ventral do saco; (48) vista ventral da valva; (49) vista ventral da juxta; (50) vista ventral do oitavo esterno; (51) vista ventral do esterigma e bolsa copuladora. Escala: $1 \mathrm{~mm}$.

Face dorsal e ventral da asa posterior: mesmo padrão de ornamentação e coloração da asa do macho, porém mais clara.

Face ventral da asa anterior: apresenta faixas intradiscal basal e distal, subdiscal e mancha subdiscal com escamas amarelas esparsas. Faixa marginal interna vestigial amarela.

Algumas fêmeas $(n=1)$ podem apresentar padrão mais melânico para todas as faixas e manchas.

Genitália feminina (Fig. 51). Esterigma trapezoidal constituído de lamela ante-vaginal suavemente côncava, formando uma pequena aba anterior ao óstio da bolsa, lamela pós-vaginal com duas projeções em forma de acúleos na porção distal. Bolsa copuladora sem forma definida, reduzida e sem signos, conectada diretamente ao óstio da bolsa circular e que abre diretamente ao exterior.

Tampão genital com a forma típica da maioria das subespécies de Actinote pellenea, retangular, relativamente largo, porém com uma torção mediana em "L deitado" com o ápice em contato com o sexto e recobrindo totalmente o sétimo esterno abdominal (PALuch et al. 2003).

Material estudado. Holótipo macho com as seguintes etiquetas:/Holotypus $/ 15^{\circ} 35^{\prime} \mathrm{S}, 47^{\circ} 42^{\prime} \mathrm{W}$, Planaltina, DF, Brasil 1000m, 17.I.1977, V.O. Becker col./Coleção EMBRAPA-CPAC $\mathrm{n}^{\mathrm{o}} 3507$ [doado ao DZUP]/Holotypus Actinote pellenea giffordi Paluch, Casagrande \& Mielke, det. 2006/DZ 9563/. Alótipo com 
as seguintes etiquetas:/Allotypus/BRASIL, Goiás Velho, D. Gifford [leg.], 12.VI.1977/ex. coleção Gifford/Allotypus Actinote pellenea giffordi Paluch, Casagrande \& Mielke, det. 2006/DZ 9289/; ambos DZUP.

Parátipos. BRASIL, Distrito Federal: Planaltina, 1000 m, $15^{\circ} 35^{\prime}$ S, $47^{\circ} 42^{\prime}$ W, 1 macho, 24.VII.1979, G.P. Santos leg., $\mathrm{n}^{\circ} 3507$

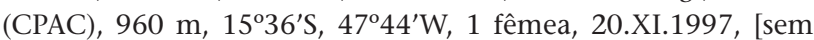
dados leg.], no 12108 (CPAC). Goiás: Cristalina, 1 macho, 24.I.1976, Gifford leg., DZ 6755 (DZUP); Goiás Velho, 1 fêmea, XI.1976, D. Gifford leg., DZ 9505 (DZUP). Paraná, Fênix, 300m, 1 macho, 29.IV.1987, Mielke \& Casagrande leg., DZ 6627 (DZUP).

Etimologia. Subespécie dedicada ao Dr. David Gifford, um dos coletores dos espécimes da série tipo.

Observações: Atualmente existem três subespécies endêmicas conhecidas para o Brasil: Actinote pellenea pellenea Hübner, [1821] de ampla distribuição espacial, com populações desde o sul da Bahia até os estados de Espírito Santo, Rio de Janeiro, Minas Gerais, São Paulo, Paraná, Santa Catarina e Rio Grande do Sul, ocupando três províncias biogeográficas Mata Atlântica, Mata Paranaense e Mata de Araucária; Actinote pellenea auloeda Oberthür, 1917 com espécimes conhecidos apenas em Pernambuco e Paraíba, constituem uma população extremamente localizada na Caatinga e Actinote pellenea giffordi, com uma distribuição na região central até o norte do Paraná, ocupando principalmente o cerrado brasileiro, distingui-se facilmente das populações de $A$. pellenea pellenea e A. pellenea auloeda, por apresentar um padrão de coloração ocráceo sobre fundo castanho em ambas as asas.

\section{AGRADECIMENTOS}

A Amabílio J.A. Camargo, curador da Coleção Entomológica EMBRAPA-CPAC, pela doação dos holótipos de Actinote morio beckeri e Actinote pellenea giffordi ao DZUP. As figuras 2-5 foram fotografadas por Francisco Santana.

\section{REFERÊNCIAS BIBLIOGRÁFICAS}

ACKERY, P.R.1984. Systematic and faunistic studies on butterflies, p. 9-21. In: R.I. Vane-Wright \& P.R. Ackery (Eds). The Biology of Butterflies. London, Academic Press, 429p.

Brown JR., K.S. 1992. Borboletas da Serra do Japi: diversidade, hábitats, recursos alimentares e variação temporal, p. 142187. In: L.P.C. MoRellato (Ed.). História Natural da Serra do Japi. Ecologia e preservação de uma área florestal no Sudeste do Brasil. Campinas, Editora UNICAMP/FAPESP, 321p.

Brown JR., K.S. \& W.W. Benson. 1974. Adaptive polimorphism associated with multiplie müllerian mimicry in Heliconius $n u-$ mata (Lep. Nymph.). Biotropica, Lawrence, 6 (4): 205-228.

Brown JR., K.S. \& R.B. FrancinI. 1990. Evolutionary strategies of chemical defense in aposematic butterflies: cyanogenesis in Asteraceae-feeding American Acraeinae. Chemoecology, Basel, 1 (2): 52-56.

D'Almeida, R.F. 1922. Mélanges lépidoptérologiques. Etudes sur les lépidoptères du Brésil. Berlin, R. Friedlãnder \& Sohn, VIII+226p.

D'Almeida, R.F. 1925. Quelques rectifications sur les Actinote de la partie orientale de l'Amérique du Sud (Lép. Rhopalocères). Annales de la Société entomologique de France, Paris, 94 (3): 333-354.

D'Almeida, R.F. 1931. Beiträge zur Schmetterlings-Fauna SüdAmerikas. Berliner Entomologische Zeitschrift, Berlin, 45 (4): 59-61.

D'Almeida, R.F. 1934. Zwei neue Schmetterlinge aus Brasilien. Berliner Entomologische Zeitschrift, Berlin, 48 (12): 9092.

D'Almeida, R.F. 1935a. Les Actinote de la partie orientale de l'Amérique du Sud. Annaes da Academia brasileira de Sciencias, Rio de Janeiro, 7 (1): 69-88, (2): 89-112.

D'Almeida, R.F. 1935b. Nota supplementar ao nosso artigo sobre o gênero Actinote Hubn. Revista de Entomologia, Rio de Janeiro, 5 (4): 486-488.

D'AlmeidA, R.F. 1943. Algumas observações sobre Actinote morio Oberthuer, 1917 (Lep. Heliconiidae, Acraeinae). Papéis avulsos do Departamento de Zoologia. Secretaria da Agricultura, São Paulo, 3 (6): 107-109.

D'Almeida, R.F. 1951. Uma nova espécie de Actinote do Sul do Brasil (Lepidoptera Heliconiidae, Acraeinae). Arquivos do Museu Nacional, Rio de Janeiro, 42 (1): 3-5.

D'Almeida, R.F. 1958. Ligeiras notas sobre algumas Actinote do sudeste do Brasil (Lepidoptera-Rhopalocera). Boletim do Museu Nacional (Zoologia), Rio de Janeiro, 178: 1-7.

Ehrlich, P.R. 1958. The comparative morphology, phylogeny and higher classification of butterflies. The University of Kansas Scientific Bulletin, Kansas, 39 (8): 305-370.

Eltringham, H. \& H.E.K. Jordan. 1913. Nymphalidae: Subfam. Acraeinae. Lepidopterorum Catalogus, 11, 65p.

Francini, R.B.; A.V.L. Freitas \& C.M.Penz. 2004. Two new species of Actinote (Lepidoptera, Nymphalidae) from Southeastern Brasil. Zootaxa, Auckland, 719: 1-10.

Francini, R.B.; A.V.L. Freitas \& K.S. Brown Jr. 2005. Rediscovery of Actinote zikani D' Almeida (Nymphalidae, Heliconiinae, Acraeini): Natural history, population biology and conservation of an endangered butterfly in SE Brazil. Journal of the Lepidopterists' Society, Lawrence, 59 (3): 134-142.

Jordan, H.E.K. 1913. I. Unterfamilie: Acraeinae, p. 358-374. In: A. SeITZ (Ed.). Die Gross-Schmetterlinge der Erde. Stuttgart, Alfred Kernen. 5.

LAMAS, G. 1995. Comentarios taxonômicos y nomenclaturales sobre ninfálidos neotropicales (Lepidoptera: Nymphalidae), con la descripción de ocho subespecies nuevas. Revista Peruana de Entomología, Lima, 37: 59-71.

LAMAS, G. 1996. Lista comentada de los nombres propuestos para los Acraeini neotropicales, y su material-tipo (Lepidoptera: Nymphalidae, Heliconiinae). Revista Peruana de Entomología, Lima, 39: 29-48.

Lamas, G. 2004. Heliconiinae, p. 262-274. In: G. Lamas (Ed.).

Revista Brasileira de Zoologia 23 (3): 764-778, setembro, 2006 
Checklist: Part 4A, Hesperioidea - Papilionoidea, 439p. In: J. B. Heprner (Ed.). Atlas of Neotropical Lepidoptera. Gainesville, Association for Tropical Lepidoptera, Scientific Publishers.

Mielke, O.H.H.; A.H. Wieloch; A.B. Machado; A. Lise; E.O. Cisalpino; G.W. Fernandes; G. Righi; K.S. Brown Jr; L.A.O. Campos; M. de Maria; M.M. Casagrande \& P. de Marco Jr. 1997. Insecta, p.23; Arthropoda, p. 47-50. In: L.V. Lins; A.B. MaChado; C.M.R. CosTA \& G. Hermann. Roteiro metodológico para elaboração de listas de espécies ameaçadas de extinção. Contendo a lista oficial de fauna ameaçada dee Minas Gerais. Publicações Avulsas da Fundação Biodiversitas, Belo Horizonte, 1: 1-50.

NijHout, H.F. 1991. Pattern elements and Homologies, p. 23-50. In: H.F. NijHоuт (Ed.). The development and evolution of butterfly wing patterns. Washington, Smithsonian Institution, $197 \mathrm{p}$.

Paluch, M.; M.M. Casagrande \& O.H.H. Mielke. 1999. Estágios imaturos de Actinote surima (Schaus) (Lepidoptera, Nymphalidae, Acraeinae). Revista Brasileira de Zoologia, Curitiba, 16 (Supl. 2): 129-140.

Paluch, M.; M.M. Casagrande \& O.H.H. Mielke. 2001. Estágios imaturos de Actinote carycina Jordan (Lepidoptera, Nymphalidae, Acraeinae). Revista Brasileira de Zoologia, Curitiba, 18 (3): 883-896.

Paluch, M.; M.M. Casagrande \& O.H.H. Mielke. 2003. Tampão genital de Actinote Hübner, como caráter taxonômico. (Lepidoptera, Nymphalidae, Acraeinae). Revista Brasileira de Entomologia, Curitiba, 47 (4): 573-580.

Paluch, M.; M.M. Casagrande \& O.H.H. Mielke. 2005. Comportamento de agregação noturna dos machos de Actinote surima surima (Schaus) (Lepidoptera, Heliconiinae, Acraeini). Revista Brasileira de Zoologia, Curitiba, 22 (2): 410-418.

Penz, C.M. 1999. Higher level phylogeny for the passion-vine butterflies (Nymphalidae, Heliconiinae) based on early stage and adult morphology. Zoological Journal of the Linnean Society, London, 127: 277-344.

Penz, C.M. \& R.B. Francins. 1996. New species of Actinote Hübner (Nymphalidae: Acraeinae) from Southeastern Brazil. Journal of the Lepidopterists' Society, Lawrence, 50 (4): 309-320.

Penz, C.M. \& P. DJunijantr. 2003. Phylogenetic relationships among Heliconiinae genera based on morphology (Lepidoptera: Nymphalidae). Systematic Entomology, London, 28: 451-479.

PIERRE, J. 1985a. Morphologie des griffes de Acraeinae (Lépidoptères Nymphalides). Comptes Rendus hebdomadaires des Séances de l'Académie des Sciences de Paris (3) 300 (8): 333-336.

PIERRE, J. 1985b. Morphologie comparée de l'appareil génital mâle des Acraeinae (Lepidoptera, Nymphalidae). Annales de la Société entomologique de France, Paris, 21 (4): 381-391.

PierRe, J. 1985c. Les sphragis chez les Acraeinae (Lepidoptera, Nymphalidae). Annales de la Société entomologique de France, Paris, 21 (4): 393-398.

Pierre, J. 1986. Morphologie comparée de l'appareil genital femelle des Acraeinae (Lepidoptera, Nymphalidae). Annales de la Société entomologique de France, Paris, 22 (1): 53-65.

Pierre, J. 1987. Sistématique cladistique chez les Acraea (Lepidoptera, Nymphalidae). Annales de la Société entomologique de France, Paris, 23 (1): 11-27.

PotTs R W L. 1943. Systematic notes concerning American Acraeinae (Lepidoptera: Nymphalidae), Pan-Pacific Entomologist, Sacramento, 19 (1): 31-32.

Recebido em 12.VIII.2005; aceito em 23.VIII.2006.

Revista Brasileira de Zoologia 23 (3): 764-778, setembro, 2006 